Available online at

SciVerse ScienceDirect

www.sciencedirect.com
Elsevier Masson France

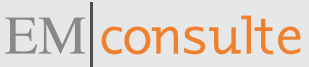

www.em-consulte.com

\title{
Susceptibility to caspofungin of Candida spp. strains isolated in Ceará, Northeastern Brazil
}

\section{Sensibilité à la caspofungine de souches de Candida sp. isolées en Ceará, Nord-est Brésilien}

\section{Rocha da Silva ${ }^{\text {a,b }}$, R. de Sousa Campos ${ }^{\text {a,b }}$, M. Adalgiza dos Santos Neta ${ }^{a, b}$, M. Rozellê Ferreira Ângelo ${ }^{c}, H$. lury Ferreira Magalhães ${ }^{a, d}$, B. Coêlho Cavalcanti ${ }^{d}, M$. Odorico de Moraes ${ }^{d}$, D. Silveira Macedo ${ }^{d}$, H. Vitoriano Nobre Júnior ${ }^{a, b, d, *}$}

\author{
a Department of Clinical and Toxicological Analysis, School of Pharmacy, Laboratory of Bioprospection and \\ Experiments in Yeast (LABEL), Federal University of Ceará, Fortaleza, CE, Brazil \\ ${ }^{\mathrm{b}}$ Department of Pathology and Legal Medicine, School of Medicine, Specialized Medical, Mycology Center, \\ Federal University of Ceará, Fortaleza, CE, Brazil \\ ${ }^{c}$ Central Public Health Laboratory (LACEN-CE), Fortaleza, CE, Brazil \\ ${ }^{\mathrm{d}}$ Department of Physiology and Pharmacology, Federal University of Ceará, Fortaleza, CE, Brazil
}

Received 1 August 2011; received in revised form 15 September 2011; accepted 23 September 2011

Available online 9 November 2011

\section{KEYWORDS \\ Caspofungin; Candida spp.; Microdilution; Susceptibility tests}

\section{MOTS CLÉS}

Caspofungine ;

Candida sp. ;
Summary Caspofungin is an echinocandin prescribed for the treatment of invasive fungal infections caused by Candida spp. and Aspergillus spp. The aim of this study is to assess the degree of susceptibility of Candida spp., isolated from blood cultures in the state of Ceará (Brazil) to caspofungin by the broth microdilution method. Thirty-three strains of Candida spp. were selected for the test (seven $C$. albicans, nine $C$. tropicalis and 17 C. parapsilosis); these strains are the most commonly isolates of fungal infections in Ceará. The results of susceptibility tests by broth microdilution can be read at $\mathbf{2 4}$ or $\mathbf{4 8}$ hours after testing, without compromising test interpretations. $C$. parapsilosis exhibited the highest MICs when compared with the MICs of caspofungin against $C$. albicans and $C$. tropicalis.

(C) 2011 Elsevier Masson SAS. All rights reserved.

Résumé La caspofungine est une échinocandine prescrite pour le traitement des infections fongiques invasives causées par Candida sp. et Aspergillus sp. Le but de cette étude est d'évaluer le degré de sensibilité à la caspofungine de Candida sp., isolé à partir d'hémocultures dans l'état du Ceará (Brésil) par la méthode de microdilution. Trente-trois souches de Candida sp. ont été

\footnotetext{
* Corresponding author. Capitão Francisco Pedro, 1210, CEP-60.420-970 Rodolfo Teófilo, Brazil.

E-mail address: helioufc@yahoo.com.br (H. Vitoriano Nobre Júnior).
} 
Microdilution ;

Tests de sensibilité sélectionnées pour le test (sept $C$. albicans, neuf $C$. tropicalis et 17 C. parapsilosis) ; ces souches sont le plus souvent isolées dans des infections fongiques en Ceará. Les résultats des tests de sensibilité par microdilution peuvent être lus à 24 ou 48 heures après les tests, sans compromettre les interprétations du test. $C$. parapsilosis montre les CMI les plus élevées comparativement à celles de $C$. albicans et $C$. tropicalis pour la caspofungine.

(C) 2011 Elsevier Masson SAS. Tous droits réservés.

\section{Introduction}

Candida albicans is the species most commonly isolated from patients with invasive fungal infections (IFIs); however, C. tropicalis and C. parapsilosis are increasingly prevalent and are the principal species isolated in Brazil [8,14,22,16].

Echinocandins are the newest class of antifungal drugs approved by the Food and Drug Administration (FDA) for the treatment of systemic fungal infections. This was the first class of antifungal agents to exhibit action on the cell wall, by inhibiting the enzyme $(1,3)$ beta-glucan synthase. Echinocandins exhibit a limited spectrum of action compared to azoles. However, they are excellent agents for the treatment of candidiasis. The primary constituents of this group are: caspofungin, micafungin and anidulafungin $[11,3,5,9,18,12]$.

There is no in vitro susceptibility testing with echinocandins against Candida spp. isolated from blood cultures in Ceará. The aim of this study is to evaluate the susceptibility of strains of C. albicans, C. tropicalis and C. parapsilosis against caspofungin by the broth microdilution method, and to compare the effectiveness of caspofungin against these strains.

\section{Materials and methods}

\section{Isolation and identification of fungal strains}

We used 33 strains of Candida spp. (seven C. albicans, nine C. tropicalis and 17 C. parapsilosis), the strains were isolated from blood cultures, between 2009 and 2010, and are part of the Collection of Yeasts of the Laboratory of Bioprospection and Experiments in Yeast (LABEL), Department of Clinical and Toxicological Analysis, College of Pharmacy, Federal University of Ceará. The strains were inoculated on potato agar (Himedia Mumbai, India) and incubated at $37^{\circ} \mathrm{C} / 24 \mathrm{~h}$. They were then plated on CHROMagar Candida (Himedia Mumbai, India) to assess purity. Identification was done by micromorphology on rice agar Tween 80 , germ tube production, fermentation and assimilation of carbohydrates, as well as molecular tests $[7,2]$.

\section{Susceptibility testing}

Caspofungin (Sigma, St Louis, MO) was prepared in water, and diluted in RPMI 1640 medium (Sigma, St. Louis, MO) buffered to $\mathrm{pH} 7.0$ with $0.165 \mathrm{M}$ MOPS (morpholinepropanesulfonic acid) buffer (Sigma). The microdilution testing was performed in accordance with the guidelines in CLSI document M27-A3 (CLSI 2008). MICs were determined visually, after $24 \mathrm{~h}$ and $48 \mathrm{~h}$ of incubation, as the lowest concentration in microgram per millilitre of drug that caused a significant diminution of $50 \%$ and $90 \%$ inhibition of growth below control levels. Quality control was performed by strains C. krusei ATCC 6258 and C. parapsilosis ATCC 22019.

\section{Results and discussion}

Treatment of systemic mycoses is one of the foremost problems in the field of medical mycology; these infections affect patients with predisposing factors. Such pathologies are difficult to detect and the delay in diagnosing them is the reason for high mortality. The antifungal agents available today often show secondary and side effects because their therapeutic margin is narrow, which limits usage of such agents [20]. Testing for susceptibility to antifungal agents has become very important due to the emergence of fungi exhibiting some degree of resistance to drugs commonly used in clinical medicine $[23,21]$. In northeastern Brazil, there are very few studies that assess the incidence of fungal infections and the profile of drug susceptibility. What we observed in clinical practice, on a cultural basis, was the prescription of antifungal drugs without prior susceptibility testing. There is an overall lack of trained professionals and reference laboratories with qualified and knowledgeable personnel, and most importantly, a lack of integration between laboratories and hospitals. Echinocandins are attractive therapeutic options for the treatment of IFIs. Although these agents have a narrow spectrum, they cover the two most common IFIs, candidiasis and aspergillosis [3]. Echinocandins exhibit few interactions with other drugs, low toxicity, and are broadly active against azole-resistant Candida spp. [5]. Table 1 shows the geometric mean (GM) of MICs $50 \%$ and $90 \%$ at 24 and 48 hours of caspofungin against C. albicans, C. parapsilosis and C. tropicalis. From a microbiological viewpoint, we see that the GM of the $50 \%$ and $90 \%$ MICs at 24 and 48 hours of $C$. parapsilosis is higher when compared to the GM of the $50 \%$ and $90 \%$ MICs at 24 and 48 hours of C. albicans and C. tropicalis; this difference was statistically significant with $P<0.05,24$ and 48 hours of caspofungin vis-a-vis $C$. albicans, $C$. parapsilosis and C. tropicalis. Epidemiological studies conducted in different regions of Latin America, including Brazil, have indicated that $C$. albicans is the most commonly isolated species, followed by $C$. tropicalis and $C$. parapsilosis [22]. C. parapsilosis is one of the foremost causes of invasive candidiasis [14]. In our study, it was the principal strain isolated (17 strains) (Table 1). Treatment of IFls requires an understanding of the epidemiology of specific infections. Echinocandins represent one of the mainstays in the treatment against candidiasis, and should be monitored by identifying the most frequent species, as well as the susceptibility of such species to drugs used previously [5]. In our study, the GM of the MICs of $C$. parapsilosis compared to $C$. albicans and $C$. tropicalis was higher, showing that $C$. parapsilosis 
Table 1 In vitro activity of caspofungin against Candida spp. Activité in vitro de la caspofungine contre Candida sp.

\begin{tabular}{|c|c|c|c|c|c|c|c|}
\hline \multirow[t]{3}{*}{ Species ( ${ }^{\circ}$ of isolates) } & \multirow[t]{3}{*}{ Time } & \multicolumn{5}{|c|}{ Caspofungin $\mathrm{MIC}^{\mathrm{a}}$} & \multirow[t]{3}{*}{$P$ value } \\
\hline & & \multicolumn{3}{|l|}{ GM } & \multicolumn{2}{|l|}{$R^{\mathrm{b}}$} & \\
\hline & & $50 \%$ & $90 \%$ & Range & $24 \mathrm{~h}$ & $48 \mathrm{~h}$ & \\
\hline \multirow[t]{2}{*}{ C. albicans (7) } & 24 & 0.06 & 0.07 & $\leq 0.06-0.12$ & 1 & 0.7 & $0.03^{c}$ \\
\hline & 48 & 0.06 & 0.07 & $\leq 0.06-0.12$ & & & \\
\hline \multirow{2}{*}{ C. tropicalis (9) } & 24 & 0.06 & 0.06 & $\leq 0.06$ & 1 & 1 & $0.01^{d}$ \\
\hline & 48 & 0.06 & 0.06 & $\leq 0.06$ & & & \\
\hline \multirow[t]{2}{*}{ C. parapsilosis (17) } & 24 & 0.07 & 0.09 & $\leq 0.06-0.25$ & 0.5 & 0.5 & \\
\hline & 48 & 0.10 & 0.17 & $\leq 0.06-0.50$ & & & \\
\hline \multirow[t]{2}{*}{ Overall (33) } & 24 & 0.07 & 0.08 & $\leq 0.06-0.25$ & 0.6 & 0.5 & \\
\hline & 48 & 0.08 & 0.11 & $\leq 0.06-0.50$ & & & \\
\hline
\end{tabular}

exhibits higher MICs for caspofungin; similar observations have been described in the literature $[9,18,1,4,19]$.

The Pearson coefficient $(R)$ was used to assess the correlation of the laboratory results at 24 and 48 hours. One can see a strong correlation between the results read after these periods of time, suggesting that there is no difference in the release of results at 24 or 48 hours after testing, thereby speeding up not only diagnosis, but also establishment of the appropriate therapy. This coefficient is a measure of the degree of linear relationship between two quantitative variables, used in several studies to correlate laboratory procedures and time of operationalization $[6,13,17]$.

Prescribing caspofungin without prior susceptibility testing may compromise the treatment of infections caused by C. parapsilosis, which in our study and in other studies have been shown to be less susceptible to caspofungin $[9,18,1,4,19]$. The union between susceptibility testing and prior identification of the causative agent is essential for establishing the correct treatment. The GM of the high MICs found in the strains of $C$. parapsilosis can be explained by the presence of the mutation on the $f k s$ gene already reported in other studies. C. parapsilosis, Candida metapsilosis, and Candida orthopsilosis, which harbor a naturally occurring amino acid substitution in the equivalent position of Fks1p. $[10,15]$. Future studies are required to evaluate this mutation and the MICs found.

\section{Disclosure of interest}

The authors declare that they have no conflicts of interest concerning this article.

\section{Acknowledgements}

This study was supported by Conselho Nacional de Desenvolvimento Científico e Tecnológico (CNPq), Coordenação de
Aperfeiçoamento de Pessoal de Nível Superior (CAPES) and Fundação Cearense de Apoio ao Desenvolvimento Científico e Tecnológico (FUNCAP).

\section{References}

[1] Andes D, Diekema DJ, Pfaller MA, Bohrmuller J, Marchillo K, Lepak A. In vivo comparison of the pharmacodynamic target among echinocandin drugs and Candida species. Antimicrob Agents Chemother 2010;54:2497-506.

[2] Azevedo AC, Bizerra FC, Matta DA, Almeida LP, Rosas R, Colombo AL. In vitro susceptibility of a large collection of Candida strains against fluconazole and voriconazole by using the CLSI disk diffusion assay. Mycopathologia 2011;171:411-6.

[3] Bal AM. The echinocandins: three useful choices or three too many? Int J Antimicrob Agents 2010;35:13-8.

[4] Cantón E, Espinel-Ingroff A, Pemán J, del Castillo L. In vitro fungicidal activities of echinocandins against Candida metapsilosis, C. orthopsilosis, and C. parapsilosis evaluated by timekill studies. Antimicrob Agents Chemother 2010;54: 2194 7.

[5] Chen SCA, Playford EG, Sorrell TC. Antifungal therapy in invasive fungal infections. Curr Opin Pharm 2010;10:522-30.

[6] Clinical and Laboratory Standards Institute - CLSI. Reference method for broth dilution antifungal susceptibility testing of yeasts: informational supplement, M27-A3. Clinical and Laboratory Standards Institute, Wayne, PA; 2008.

[7] Colombo AL, Nucci M, Park BJ, et al. Epidemiology of candidemia in Brazil: a nationwide sentinel surveillance of candidemia in eleven medical centers. J Clin Microbiol 2006;44:2816-23.

[8] Colombo AL, Bourque M, Ngai AL, et al. Caspofungin use in patients with invasive candidiasis caused by common non-albicans Candida species: review of the Caspofungin database. Antimicrob Agents Chemother 2010;54:1864-71.

[9] Denning DW, Hope WW. Therapy for fungal diseases: opportunities and priorities. Trends Microbiol 2010;18:195-204.

[10] Garcia-Effron G, Katiyar SK, Park S, Edlind TD, Perlin DS. A naturally occurring proline-to-alanine amino acid change in fks1p in Candida parapsilosis, Candida orthopsilosis, and 
Candida metapsilosis accounts for reduced echinocandin susceptibility. Antimicrob Agents Chemother 2008;52:2305-12.

[11] Hazen KC, Dirks D, Masuoka J. Determination of Echinocandin MICs for Candida species in less than 8 hours: comparison of the rapid susceptibility assay with the clinical and laboratory Standards Institute's Broth Microdilution Assay. J Clin Microbiol 2009;47:4043-8.

[12] Lanternier F, Lortholary O. Caspofungin. J Mycol Med 2010; 20:190-3.

[13] Mainda CM, Milici ME, Trovato L, et al. Evaluation of the disk diffusion method compared to the microdilution method in susceptibility testing of anidulafungin against filamentous fungi. J Clin Microbiol 2008;46:4071-4.

[14] Miceli MH, Díaz JA, Lee SA. Emerging opportunistic yeast infections. Lancet Infect Dis 2011;11:142-51.

[15] Mirhendi H, Bruun B, Christensen JJ, Schonheyder HC, et al. Molecular screening for Candida orthopsilosis and Candida metapsilosis among Danish Candida parapsilosis group blood culture isolates: proposal of a new RFLP profile for differentiation. J Med Microbiol 2010;59:414-20.

[16] Münoz P, Guinea J, Rojas L, Bouza E. New antifungal agents for the treatment of candidaemia. Int $\mathrm{J}$ Antimicrob Agents 2010;36S:S63-9.

[17] Pfaller MA, Diekema DJ, Ostrosky-Zeichner L, et al. Correlation of MIC with outcome for Candida species tested against Cas- pofungin. Anidulafungin, and Micafungin: analysis and proposal for interpretive MIC breakpoints. J Clin Microbiol 2008;46: 2620-9.

[18] Pfaller MA, Castanheira M, Diekema DJ, Messer SA, Moet GJ, Jones RN. Comparison of European Committee on Antimicrobial Susceptibility Testing (EUCAST) and Etest Methods with the CLSI Broth Microdilution Method for Echinocandin susceptibility testing of Candida species. J Clin Microbiol 2010;48: 1592-9.

[19] Pfaller MA, Andes D, Diekma DJ, et al. Clinical breakpoints for the echinocandins and Candida revisited: integration of molecular, clinical, and microbiological data to arrive at species-specific interpretive criteria. Drug Resist Updat 2011;14:164-76.

[20] Ruiz-Camps I, Cuenca-Estrella M. Antifúngicos para uso sistêmico. Enferm Infecc Microbiol Clin 2009;27:353-62.

[21] Sabra W, Tawfik AF, Shibl AM. Evaluation of a new method for antifungal susceptibility testing for azoles. World J Microbiol Biotechnol 2010;26:451-7.

[22] San-Blas G, Burger E. Experimental medial mycological research in Latin America 2000-2009 overview. Rev Iberoam Micol 2011;28:1-25.

[23] Silva AP, Miranda IM, Lisboa C, Pina-Vaz C, Rodrigues AG. Prevalence, distribution, and antifungal Susceptibility profiles of Candida parapsilosis, C. orthopsilosis, and C. metapsilosis in a tertiary care hospital. J Clin Microbiol 2009;47:2392-7. 